\title{
Estudo comparativo dos custos da implantação de rede de abastecimento de água no distrito de Luzimangues/TO
}

A água é um dos recursos naturais essenciais à sobrevivência humana, no entanto tem sofrido com problemas como sobrecarga de utilização, em âmbito global e escassez, o que contribui de forma negativa com a disponibilidade do recurso, evidenciando assim, a crise da água. Neste contexto, surge então a necessidade de se gerenciar de maneira eficaz esse recurso que é tão importante e que apresenta inúmeros componentes de incertezas. Um importante objeto do gerenciamento é o tratamento químico pelo qual a água bruta passa para se tornar potável e adequada para o consumo humano, este processo corresponde ao segundo maio custo nas estações de tratamento de água, atrás apenas de despesas envolvendo recursos humanos, materiais e serviços. Neste trabalho buscou-se mostrar, através de revisão bibliográfica, a íntima relação existente entre saneamento básico, meio ambiente e saúde pública. Concluiu-se que o saneamento básico é um fator fundamental, mas não único, para a melhoria da qualidade de vida da população, devendo ser incorporado a um modelo de desenvolvimento que contemple também as questões econômicas e sociais.

Palavras-chave: Recursos naturais; Saneamento básico; Macroestrutura; Tratamento químico.

\section{Comparative study of the costs of implementing a water supply network in the district of Luzimangues Municipality/TO}

\begin{abstract}
Water is one of the natural resources essential to human survival, however it has suffered from problems such as overload of use, globally and scarcity, which contributes negatively to the availability of the resource, thus evidencing the water crisis. In this context, the need arises to effectively manage this resource, which is so important and which has numerous components of uncertainty. An important object of management is the chemical treatment that raw water undergoes to become potable and suitable for human consumption, this process corresponds to the second highest cost in water treatment plants, behind only expenses involving human, material and services. In this work, we sought to show, through bibliographic review, the intimate relationship between basic sanitation, the environment and public health. It was concluded that basic sanitation is a fundamental factor, but not the only one, for improving the quality of life of the population, and should be incorporated into a development model that also includes economic and social issues.

Keywords: Natural resources; Basic sanitation; Macrostructure; Chemical treatment.
\end{abstract}

Topic: Engenharia de Construção Civil

Reviewed anonymously in the process of blind peer
Received: 25/11/2019

Approved: 21/03/2020

Wislley Cardoso Sardinha

Centro Universitário Católica do Tocantins, Brasil

http://lattes.cnpq.br/6484420685634374

wislleycardoso@gmail.com

Flavio Vieira da Silva Junior

Centro Universitário Católica do Tocantins, Brasil

http://lattes.cnpq.br/2211436659738090

flavio.junior@p.catolica-to.edu.br

d

DOI: 10.6008/CBPC2674-6425.2020.002.0003
Referencing this:

SARDINHA, W. C.; SILVA JUNIOR, F. V.. Estudo comparativo dos custos da implantação de rede de abastecimento de água no distrito de Luzimangues/TO. Technology Science, v.2, n.2, p.30-37, 2019. DOI: http://doi.org/10.6008/CBPC2674-6425.2020.002.0003 


\section{INTRODUÇÃO}

O custo é definido como sacrifício de recursos para conseguir atingir um determinado objetivo, já as funções do custo são definidas como sendo atividades associadas à produção de uma quantidade de uma determinada variável ao custo total.

Os custos associados à implantação de redes de distribuição de água deverão ter um dimensionamento econômico adequado, pois tem sido objeto de estudo de diversos pesquisadores e projetistas, já que representa uma relevante parte nas ações de saneamento básico.

O dimensionamento de condutos é necessário para atingir uma rede de menor custo e que satisfaça os pré-requisitos hidráulicos mínimos de dimensionamento. Isso conduz necessariamente à escolha de uma rede cuja combinação de condutos de menor diâmetro possível e que também seja capaz de satisfazer as restrições hidráulicas.

Na construção civil por meio de conhecimentos básicos de orçamento, de cálculos matemáticos, de dimensionamento de estruturas, materiais e execução, contribuem para um equilíbrio entre o custo de implantação e o custo de manutenção da rede de distribuição de água (SILVA et al., 2017).

Na ABNT (NBR 12266, 1992), existe a definição onde, esta norma estabelece os requisitos para a elaboração de projeto de distribuição de água para abastecimento público.

A Importância da implantação da rede de distribuição melhora a qualidade da água para a população no aspecto sanitário e nas condições de vida de uma comunidade, principalmente através do controle e prevenção de doenças.

\section{REVISÃO TEÓRICA}

O abastecimento de água, tanto em quantidade quanto em qualidade é de suma importância para a sociedade, uma vez que tem influência direta na área da saúde e meio ambiente, o que consequentemente altera a qualidade de vida e a capacidade de desenvolvimento da população, além de ser um direito básico garantido pela nossa Constituição.

No Brasil, para a maior parte dos municípios, a universalização do acesso a água não é uma realidade distante, o percentual de municípios com abastecimento de água por rede chegou a 99,6\% (5.548 municípios) em 2017, sendo que essa rede estava em funcionamento em 5.517, paralisada em 22 e em implantação em nove, segundo dados do PNSB (Pesquisa Nacional de Saneamento Básico). Apesar dos bons números e da boa disponibilidade hídrica que ainda temos, retratada pelos altos valores de consumo per capita, para compreender a situação real do abastecimento seriam necessários diversos outros indicadores, como os de qualidade de água e continuidade de abastecimento (CONAMA, 2005).

\section{Sistema de abastecimento}

O abastecimento de água desde os reservatórios de distribuição até os pontos de consumo da cidade realiza-se através de uma ou várias redes de distribuição, com finalidade de garantir que em cada ponto 
consumidor a água chegue com vazão precisa, pressão suficiente e que sua qualidade não seja deteriorada. Um dos principais problemas que afetam a eficiência dos serviços de abastecimento de água é o grande desperdício do recurso e a elevada perda de água que ocorre nos sistemas de abastecimento.

A melhor saída para o abastecimento de água, é a solução coletiva, exceto no caso das comunidades rurais que se encontram muito afastadas. As partes do Sistema Público de Água são: captação; adução (transporte); tratamento; reservação (armazenamento) e distribuição.

Portanto, ainda segundo o autor supracitado, o sistema de abastecimento de água é composto por: manancial (fonte de onde se retira a água), captação (conjunto de equipamentos e instalações utilizado para a tomada de água do manancial), adução (transporte da água do manancial para a estação de tratamento de água para a reservação), tratamento (melhoria das características qualitativas da água), reservação (armazenamento da água) e por fim, rede de distribuição (condução da água para os pontos de consumo).

\section{Propriedades dos materiais}

O material utilizado para obras de saneamento tem seus critérios adotados para que sejam empregados nas redes de distribuição de água, Tsutiya (2006) afirma que alguns fatores devem ser levados em conta além da resistência dos tubos, tais como a durabilidade, material da superfície interna (deve permitir boa condução da água e não deve reagir ao seu contato para que não afete o fluxo, material da superfície externa (deve ter resistência a corrosão), instalação (deve-se levar em conta o peso, tipo de junta, diâmetros disponíveis, facilidade de interligações, condições do solo, topografia do terreno e nível do lençol freático para que se obtenha melhor custo benefício na execução).

O autor destaca que além destas características deve-se atender ainda a legislação local, condições de tempo de instalação, resistência ao fogo, a exposição da tubulação e as especificações dos materiais previstas em normas.

\section{Custos de implantação de rede de abastecimento}

Um dos principais empecilhos referentes a expansão do sistema de tratamento de água no país é o elevado custos de implantação, posto que este se encontra relacionado ao material, o tipo de concepção entre outros fatores. O que deve ser levado em conta é a diferença dos resultados obtidos com o custo inicial, tanto no aspecto econômico quanto em qualidade de vida da população.

De modo geral, os custos relacionados a implantação e operação de uma rede de distribuição de água, dentro de condições definidas por projetos como demanda e traçado da rede, depende da cota piezométrica do ponto de alimentação da rede, ela sendo abastecida por reservatório elevado ou por sistema de bombeamento direto.

Esses custos também contemplam os diâmetros necessários para o funcionamento da rede e o material da tubulação. A partir daí, parte-se da premissa que quanto maior a cota piezométrica do ponto de alimentação, menor o custo para a implantação da rede, com a possibilidade de se adotar tubos com diâmetros menores, pois as cargas no sistema serão hábeis a superar as perdas de cargas. 
Por outro lado, o custo relacionado à operação da rede de um sistema de bombeamento aumenta em função da cota piezométrica de alimentação, pois gera maior gastos com a energia. Por isso, sempre será necessário fazer um balanceamento entre custo de implantação de operação.

\section{Melhoria na qualidade de vida}

A importância da implantação do sistema de abastecimento de água, dentro do contexto do saneamento básico, deve ser considerada tanto no aspectos sanitário e social quanto nos aspectos econômicos (RIBEIRO et al., 2010), a fim de, atingir objetivos nos aspectos sanitário e social, tais como melhoria da saúde e das condições de vida de uma comunidade; diminuição da mortalidade em geral, principalmente da infantil; aumento da esperança de vida da população; diminuição da incidência de doenças relacionadas à água; implantação de hábitos de higiene na população; facilidade na implantação e melhoria da limpeza pública; facilidade na implantação e melhoria dos sistemas de esgotos sanitários; possibilidade de proporcionar conforto e bem-estar; incentivo ao desenvolvimento econômico.

Nos aspectos econômicos é possível citar o aumento da vida produtiva dos indivíduos economicamente ativos; diminuição dos gastos particulares e públicos com consultas e internações hospitalares; facilidade para instalações de indústrias, onde a água é utilizada como matéria-prima ou meio de operação; incentivo à indústria turística em localidades com potencialidades para seu desenvolvimento (RIBEIRO et al., 2010).

\section{Custo benefício}

A importância do abastecimento de água em relação à mortalidade infantil, é que a torna mais eficiente economicamente do que investimentos de caráter defensivo na saúde. Somado a isso, é possível ressaltar as externalidades positivas sobre o meio ambiente do investimento em saneamento.

Partindo deste ponto, pode-se destacar que o maior benefício econômico nos serviços de abastecimento de água, é consequentemente ter custos menores com saúde pública. Segundo o Instituto Trata Brasil, o problema da gestão equivocada afeta ainda o desenvolvimento econômico e social de qualquer região. O Instituto fez um trabalho com abastecimento de água às comunidades em 2016, que resultou em $78 \%$ dos custos unitários com mortes evitadas, redução de gastos com saúde de aproximadamente $\mathrm{R} \$ 11,8$ bilhões oriundos de doenças causadas pelo consumo de água não potável. Dados do Ministério da saúde apontam que o país gastou com o SUS em 2019, R\$ 127,08 bilhões, gastos estes que poderiam ser reduzidos caso toda população brasileira fosse atendida por tal serviço.

Os benefícios oferecidos pelo tratamento de água, é indiscutível, pois transforma, após a remoção de contaminantes, água inadequada para o consumo humano em um produto que esteja em acordo com padrões de potabilidade. $\mathrm{O}$ abastecimento produz também um impacto indireto no setor econômico, pois aumento a expectativa de vida, reduz as horas perdidas de trabalho em razão de doenças por ingestão de água insalubre, além de facilitar a instalação de indústrias e promover o turismo na região (MS, 2007). 


\section{METODOLOGIA}

\section{Caracterização da área de estudo}

O estudo foi realizado em Luzimangues - TO, distrito de Porto Nacional TO, possui área de $891,8 \mathrm{~km}^{2}$ e conta com 20.000 habitantes, segundo dados da Energisa Tocantins. O município não é atendido com excelência pelo serviço de abastecimento de água, os moradores da região vivem com constantes problemas no abastecimento, ou a falta dele, que ocorre com bastante frequência, esta pesquisa tem como objetivo avaliar dados dos componentes e custo de todo sistema de fornecimento de água da região e encontrar os principais problemas no abastecimento de água.

\section{Composição dos Custos de Implantação}

Os Custos envolvendo na implantação de uma rede de distribuição de água são compostos pelos custos dos materiais envolvidos, bem como pelos serviços que serão realizados para a execução. No entanto, será abordado somente o custo de implantação, considerando custos dos condutos, por serem os elementos de maior peso no projeto.

\section{Custos}

Foram considerados os seguintes serviços para a composição dos custos de serviços, baseando-se na NBR 12.266/1992 (ABNT, 1992): locação da rede de distribuição de água, escavação mecânica de vala não escorada, com material de primeira categoria, regularização e compactação manual do fundo de vala, assentamento de tubulação em PVC, execução das ligações prediais, reaterro de valas com compactação manual das camadas, reaterro de vala com compactação mecânica. A partir dos serviços acima listados, procurou-se junto ao SINAPI (2015.b) as unidades de medição e os custos médios considerados, conforme tabela 1.

Tabela 1: Preço dos serviços normalmente empregados nas redes de distribuição de água - SINAPI (2015.b).

\begin{tabular}{|c|c|c|c|}
\hline Código SINAPI & Serviço & $\begin{array}{l}\text { Unidade de } \\
\text { Medição }\end{array}$ & Preço médio \\
\hline 73610 & Locação de redes de água ou de esgoto & $\mathrm{m}$ & $\mathrm{R} \$ 0,71$ \\
\hline 3061 & $\begin{array}{l}\text { Escavação mecânica da vala/sem escoramento material de 1ạ } \\
\text { categoria c/ retroescavadeira até } 150 \text { m excluindo esgotamento }\end{array}$ & $\mathrm{m}^{3}$ & $\mathrm{R} \$ 5,30$ \\
\hline 72915 & $\begin{array}{l}\text { Escavação mecânica de vala em material de } 2 \text { a categoria até } 2 \\
\text { m de profundidade c/ utilização de escavadeira hidráulica }\end{array}$ & $\mathrm{m}^{3}$ & $\mathrm{R} \$ 10,06$ \\
\hline 5622 & Regularização e compactação manual de terreno com soquete & $\mathrm{m}^{2}$ & $\mathrm{R} \$ 5,32$ \\
\hline $73964 / 004$ & $\begin{array}{l}\text { Reaterro de valas/cavas, compactada a maço, em camadas de } \\
\text { até } 30 \mathrm{~cm}\end{array}$ & $\mathrm{~m}^{3}$ & $\mathrm{R} \$ 33,85$ \\
\hline 79488 & Reatero manual c/ apiolamento mecânico & $\mathrm{m}^{3}$ & $\mathrm{R} \$ 7,84$ \\
\hline $73888 / 001$ & Assentamento de tubo pvc com junta elástica, dn 50 mm p/água & $\mathrm{m}$ & $\mathrm{R} \$ 1,72$ \\
\hline $73888 / 002$ & Assentamento de tubo pvc com junta elástica, dn 75 mm p/água & $\mathrm{m}$ & $\mathrm{R} \$ 2,30$ \\
\hline $74253 / 003$ & $\begin{array}{l}\text { Assentamento de tubo pvc com junta elástica dn } 100 \text { mm p/ } \\
\text { água }\end{array}$ & $\mathrm{m}$ & $\mathrm{R} \$ 2,87$ \\
\hline $73888 / 001$ & $\begin{array}{l}\text { Ramal predial em tubo pead } 20 \text { mm - fornecimento, instalação, } \\
\text { escavação e reaterro }\end{array}$ & $\mathrm{m}$ & $\mathrm{R} \$ 22,55$ \\
\hline 83878 & Ligação da rede de $50 \mathrm{~mm}$ ao ramal predial 1/2" & $\mathrm{m}$ & $\mathrm{R} \$ 36,60$ \\
\hline 83879 & Ligação da rede de 75 mm ao ramal predial 1/2" & $\mathrm{m}$ & $\mathrm{R} \$ 43,18$ \\
\hline 73692 & Lastro de areia média & $\mathrm{m}^{3}$ & $\mathrm{R} \$ 90,03$ \\
\hline
\end{tabular}


Com relação aos materiais empregados na construção da rede de distribuição de água, foram considerados os seguintes insumos: pasta lubrificante para aplicação nas juntas elásticas, anel de borracha, tubulações em PVC PBA - Classe 15, colar de tomada para interligação da rede pública às ligações prediais, tubo PEAD para ligações prediais. Buscou-se também as unidades de medição e os custos médios considerados para os insumos geralmente empregados nas redes de distribuição de água junto ao SINAPI (2015.a), conforme tabela 2.

Tabela 2: Preço dos insumos normalmente empregados nas redes de distribuição de água - SINAPI (2015a).

\begin{tabular}{|c|c|c|c|}
\hline Código SINAPI & Serviço & $\begin{array}{l}\text { Unidade de } \\
\text { Medição }\end{array}$ & Preço médio \\
\hline 73610 & $\begin{array}{l}\text { Pasta lubrificante para uso em tubos de pvc com anel de } \\
\text { borracha (pote de } 3.500 \mathrm{~g} \text { ) }\end{array}$ & un & $\mathrm{R} \$ 82,10$ \\
\hline 3061 & $\begin{array}{l}\text { Anel de borracha, para tubo/conexão PVC PBA, dn } 50 \text { mm, para } \\
\text { rede agua }\end{array}$ & un & $\mathrm{R} \$ 1,36$ \\
\hline \multirow[t]{2}{*}{72915} & $\begin{array}{l}\text { Anel de borracha, para tubo/conexão PVC PBA, dn } 75 \text { mm, para } \\
\text { rede agua }\end{array}$ & un & $\mathrm{R} \$ 4,48$ \\
\hline & $\begin{array}{l}\text { Anel de borracha, para tubo/conexão PVC PBA, dn } 100 \text { mm, para } \\
\text { rede Água }\end{array}$ & un & $\mathrm{R} \$ 3,50$ \\
\hline 5622 & $\begin{array}{l}\text { Colar de tomada pvc c/ travas saída rosável c/ bucha de latão de } \\
60 \mathrm{~mm} \times 3 / 4 " \mathrm{p} / \text { ligação predial }\end{array}$ & un & $\mathrm{R} \$ 8,99$ \\
\hline $73964 / 004$ & $\begin{array}{l}\text { Colar de tomada pvc c/ travas saída rosável c/ bucha de latão de } \\
85 \mathrm{~mm} \times 3 / 4 " \mathrm{p} / \text { ligação predial }\end{array}$ & un & $\mathrm{R} \$ 11,85$ \\
\hline 79488 & $\begin{array}{l}\text { Colar tomada pvc c/ travas, saída rosável c/ bucha de latão de } \\
110 \mathrm{~mm} \times 3 / 4 "\end{array}$ & un & $\mathrm{R} \$ 13,49$ \\
\hline $73888 / 001$ & $\begin{array}{l}\text { Tubo de polietileno de alta densidade (PEAD), pe- } 80, \text { de }=32 \mathrm{~mm} \\
\times 3,0 \mathrm{~mm} \text { de parede, } \mathrm{m} 4,46 \text { para ligação de água predial (NBR } \\
8417 \text { ) }\end{array}$ & $\mathrm{m}$ & $\mathrm{R} \$ 4,46$ \\
\hline 00009825 & Tubo PVC, DEFoFo, JEl, $1 \mathrm{mpa}$, dn $100 \mathrm{~mm}$, para rede de agua & $\mathrm{m}$ & $\mathrm{R} \$ 28,10$ \\
\hline $74253 / 003$ & Tubo PVC PBA, classe 15, je, dn 100/de 110 mm, rede agua & $\mathrm{m}$ & $\mathrm{R} \$ 31,31$ \\
\hline $73888 / 001$ & Tubo PVC PBA, classe 15, je, dn 50/de $60 \mathrm{~mm}$, rede agua & $\mathrm{m}$ & $R \$ 9,27$ \\
\hline 83878 & Tubo PVC PBA, classe 15, je, dn 75/de $85 \mathrm{~mm}$, rede agua & $\mathrm{m}$ & $\mathrm{R} \$ 17,43$ \\
\hline \multirow[t]{3}{*}{83879} & Tubo PVC PBA, classe 20 , je, dn 100/de $110 \mathrm{~mm}$, rede agua & $\mathrm{m}$ & $\mathrm{R} \$ 39,54$ \\
\hline & Tubo PVC PBA, classe 20, je, dn 50/de $60 \mathrm{~mm}$, rede agua & $\mathrm{m}$ & $\mathrm{R} \$ 11,75$ \\
\hline & Tubo PVC PBA, classe 20, je, dn 75/de $85 \mathrm{~mm}$, rede agua & $\mathrm{m}$ & $\mathrm{R} \$ 23,65$ \\
\hline 73692 & Kit cavalete com registro $3 / 4 "$ completo & un & $\mathrm{R} \$ 32,18$ \\
\hline
\end{tabular}

\section{RESULTADOS E DISCUSSÃO}

Anualmente a BRK Ambiental, empresa responsável pelo serviço de abastecimento de água e coleta de esgoto do Tocantins disponibiliza relatórios com informações sobre a qualidade da água distribuída em cada cidade do estado em cumprimento ao Decreto Presidencial no 5.440/2005, que institui mecanismos e instrumentos para divulgação de informação ao consumidor sobre a qualidade da água para consumo humano. De acordo com os dados divulgados, a qualidade da água, que é controlada durante todo o processo de tratamento, na saída do tratamento, nos reservatórios e no sistema de distribuição, atende ao Anexo XX da Portaria de Consolidação № 5 do Ministério da Saúde.

Em Luzimangues, distrito de Porto Nacional - TO, a captação da água bruta é realizada através da barragem de acumulação do Ribeirão São João, que pertence à bacia hidrográfica do Rio Tocantins, com sua nascente na Serra do Carmo, no município de Porto Nacional. As matas ciliares que protegem o manancial vêm apresentando sinais de degradação no montante da região represada, em função das atividades agropecuárias que são desenvolvidas pelos fazendeiros, já na área de represamento as matas ciliares 
encontram em bom estado de preservação, facilitando o processo produção de água potável para a população.

A água é captada através da barragem de acumulação do Ribeirão São João e passa pelos processos de tratamento, tais como, captação, adução, coagulação, dupla filtração, desinfecção, fluoretação, reservação e distribuição. Segundo a empresa, o sistema em Porto Nacional funciona em média 23,40 h/dia, atendendo $100 \%$ da população, com uma produção média de $12.347 \mathrm{~m}^{3} /$ dia e capacidade de reservação de $4.000 \mathrm{~m}^{3}$ de água tratada. Num entanto, moradores do Distrito estão constantemente descontentes com os serviços prestados, explanando inclusive suas queixas com a falta do abastecimento de água nas mídias sociais local.

A partir da determinação dos quantitativos envolvidos para a implantação de rede de distribuição de água dupla (assentadas nos dois passeios existentes na via), aplicou-se os custos estabelecidos pelo SINAPI (2015.a) e SINAPI (2015.b), conforme apresentados na Tabela 3, deste modo estimou-se os custos de serviços e materiais, respectivamente, em função do diâmetro nominal da rede.

Tabela 2: Estimativa dos custos envolvidos na implantação das redes de distribuição de água nos dois passeios em função do Diâmetro Nominal (DN) da rede.

\begin{tabular}{|c|c|c|c|c|}
\hline & Custos & DN50 & DN75 & DN100 \\
\hline \multirow[t]{3}{*}{ MATERIAL } & $\begin{array}{l}\text { Tubulação PVC (m) } \\
\text { Anéis de borracha (un.) } \\
\text { Pasta Lubrificante (g) }\end{array}$ & $\begin{array}{l}111,24 \\
2,72 \\
0,64 \\
\end{array}$ & $\begin{array}{l}209,16 \\
8,96 \\
1,04 \\
\end{array}$ & $\begin{array}{l}375,72 \\
7,00 \\
1,26 \\
\end{array}$ \\
\hline & $\begin{array}{l}\text { Subtotal (R\$ por } 6 \mathrm{~m}) \\
\text { Relação entre o custo } \\
\text { do material e o custo } \\
\text { total (\%) }\end{array}$ & $\begin{array}{l}114,60 \\
32,9 \%\end{array}$ & $\begin{array}{l}219,16 \\
47,0 \%\end{array}$ & $\begin{array}{l}383,98 \\
59,5 \%\end{array}$ \\
\hline & $\begin{array}{l}\text { Locação da rede de } \\
\text { distribuição de água } \\
\text { (m) } \\
\text { Volume Escavado - Ve } \\
\text { (m3) } \\
\text { Regularização e } \\
\text { compactação do fundo } \\
\text { de vala (m2) }\end{array}$ & $\begin{array}{l}8,52 \\
29,04 \\
38,30 \\
20,64 \\
108,32\end{array}$ & $\begin{array}{l}8,52 \\
30,10 \\
38,30 \\
27,60 \\
114,42\end{array}$ & $\begin{array}{l}8,52 \\
30,96 \\
38,30 \\
34,44 \\
120,50\end{array}$ \\
\hline \multirow[t]{2}{*}{ SERVIÇOS } & $\begin{array}{l}\text { Assentamento da } \\
\text { Tubulação }(\mathrm{m}) \\
\text { Volume de aterro com } \\
\text { apelamento manual - } \\
\text { VACM (m3) } \\
\text { Volume de aterro com } \\
\text { compactação } \\
\text { mecânica-VACMec } \\
\text { (m3) }\end{array}$ & 28,22 & 28,22 & 28,22 \\
\hline & $\begin{array}{l}\text { Subtotal (R\$ por } 6 \mathrm{~m}) \\
\text { Relação entre o custo } \\
\text { dos serviços e o custo } \\
\text { total (\%) }\end{array}$ & $\begin{array}{l}233,04 \\
67,1 \%\end{array}$ & $\begin{array}{l}247,16 \\
53,0 \%\end{array}$ & $\begin{array}{l}260,94 \\
40,5 \%\end{array}$ \\
\hline Custo Total & $\begin{array}{l}\text { Por } 6 \mathrm{~m}(\mathrm{R} \$) \\
\text { Linear }(\mathrm{R} \$ / \mathrm{m})\end{array}$ & $\begin{array}{l}347,64 \\
57,94\end{array}$ & $\begin{array}{l}466,32 \\
77,72\end{array}$ & $\begin{array}{l}644,92 \\
107,49\end{array}$ \\
\hline
\end{tabular}

Um dos principais empecilhos referentes a expansão do sistema de tratamento de água no país é o elevado custos de implantação, posto que, este se encontra relacionado ao material, o tipo de concepção entre outros fatores, num entanto é algo que reflete diretamente tanto no aspecto econômico quanto em 
qualidade de vida da população, e não é um serviço impossível de ser prestado com qualidade e segurança, tendo em vista a estimativa realizada.

\section{CONCLUSÕES}

Mesmo com a ONU declarando que o acesso à água potável e ao saneamento básico é um direito essencial do ser humano e além de ser também garantido pela Constituição Federal ainda há muitas pessoas não sabem o que é possuir água tratada em suas residências.

Dentre as melhorias nas condições de vida da população atendidas pelo tratamento de água o primeiro deles é a promoção da saúde nas atividades dirigidas à transformação dos comportamentos dos indivíduos, focando nos seus estilos de vida e localizando-os no seio das famílias e, no máximo, no ambiente das culturas da comunidade em que se encontram. Neste caso, investimentos nos programas ou atividades de promoção da saúde tendem a concentrar-se em componentes educativos, e primeiramente relacionados com riscos comportamentais passíveis de mudanças, que estariam, pelo menos em parte, sob o controle dos próprios indivíduos. Posteriormente, tais recursos que puderam ser controlados na saúde, poderiam ser investidos na educação, e lazer para a população, tendo em visto que, estes serviços ainda são parcos no país.

É evidente a importância dos serviços de saneamento básico, tanto na prevenção de doenças, quanto na preservação do meio ambiente. A inserção de aspectos ambientais nas ações de saneamento representa um avanço significativo, em termos de legislação, mas é preciso criar condições e políticas públicas para que os serviços de saneamento sejam implementados e sejam acessíveis a todos.

\section{REFERÊNCIAS}

ABNT. Associação Brasileira de Normas Técnicas. NBR 12266. Projeto e execução de valas para assentamento de tubulação de água, esgoto ou drenagem urbana. ABNT, 1992.

CONAMA. Conselho Nacional do Meio Ambiente. Resolução n. 357, de 17/03/2005. São Paulo: CONAMA, 2005.

MS. Ministério da Saúde. Portaria n. 518/GM, Anexo 1. Brasília: ANVISA, 2007
RIBEIRO, J. W.; ROOKE, J. L. M. R.. Saneamento básico e sua elação com o meio ambiente e a saúde pública. Monografia (Especialização em Análise Ambiental) - Universidade Federal de Juiz de Fora, Juiz de Fora, 2010.

SILVA, P. A.; MORAES, A. G.; FRANÇA, F. V. P.. Análise comparativa entre materiais de tubulação para construção de redes adutoras de água. São Paulo, 2017.

TSUTIYA, M. T.. Abastecimento de água: departamento de engenharia hidráulica e sanitária da escola politécnica da Universidade de São Paulo. São Paulo: EBAH, 2006.

A CBPC - Companhia Brasileira de Produção Científica (CNPJ: 11.221.422/0001-03) detém os direitos materiais desta publicação. Os direitos referem-se à publicação do trabalho em qualquer parte do mundo, incluindo os direitos às renovações, expansões e disseminações da contribuição, bem como outros direitos subsidiários. Todos os trabalhos publicados eletronicamente poderão posteriormente ser publicados em coletâneas impressas sob coordenação da Sapientiae Publishing, da Companhia Brasileira de Produção Científica e seus parceiros autorizados. Os (as) autores (as) preservam os direitos autorais, mas não têm permissão para a publicação da contribuição em outro meio, impresso ou digital, em português ou em tradução. 